\title{
Diurnal variation in peak expiratory flow rate among polyvinylchloride compounding workers
}

\author{
H S Lee, T P Ng, Y L Ng, W H Phoon
}

\begin{abstract}
The diurnal variation in peak expiratory flow rate (PEFR) was studied in 24 mixers and 24 non-mixers in three polyvinylchloride (PVC) compounding plants and 24 non-PVC controls from a marine police workshop. The three groups (all men) were matched for age, race, and smoking. The mean respirable dust concentration (essentially PVC dust) was $1.6 \mathrm{mg} / \mathrm{m}^{3}$ for mixers and $0.4 \mathrm{mg} / \mathrm{m}^{3}$ for nonmixers. The mean diurnal variation in PEFR of the mixers was $6.5 \%$. This was significantly higher than the $4 \cdot 8 \%$ for non-mixers and $4 \cdot 3 \%$ for the non-PVC controls. Six mixers had a diurnal variation of more than $15 \%$ on at least one day compared with none among the other two groups. Twenty nine per cent of mixers complained of wheezing compared with $4 \%$ of non-mixers and none among non-PVC workers. These differences were significant. Forced expiratory volume in one second $\left(F E V_{1}\right)$ for the mixers was $10 \%$ below the predicted values whereas that of non-PVC workers was $2 \%$ below predicted values. The study indicates a significant acute airway constriction from occupational exposure to PVC dust.
\end{abstract}

A case of occupational asthma due to unheated polyvinylchloride (PVC) resin dust has been reported recently. ${ }^{1}$ Both obstructive and restrictive ventilatory impairment and a high prevalence of wheezing complaints have been reported among PVC fabrication workers. ${ }^{23}$ Abnormalities of lung function have also been reported in surveys of other workers exposed to PVC dust. ${ }^{45}$

We studied the diurnal variation in the peak expiratory flow rate (PEFR) in a group of PVC compounding workers and in a control group. Our

Department of Industrial Health, Ministry of Labour, MOL Building, 18 Havelock Road, Singapore 0105

H S Lee, W H Phoon

Department of Community, Occupational, and Family Medicine, National University of Singapore, Singapore

T P Ng, Y L Ng aim was to determine whether PVC compounding workers have increased diurnal variation in PEFR suggesting exposure to a potential bronchoactive agent.

\section{Materials and Methods} MANUFACTURING PROCESS

The study was conducted in three PVC compounding factories. Polyvinylchloride pellets were produced by mixing together PVC resin powder with other additives such as plasticisers (for example di-octylphthalate), stabilisers (for example, lead sulphate), fillers (for example, calcium carbonate), and pigments. Azodicarbonamide (a blowing agent) was not used in the three factories. The bulk of the raw material was the PVC resin powder constituting more than $90 \%$ by weight of the mixture. The mixture was then blended and heated up to $170^{\circ} \mathrm{C}$ and extruded as pellets.

The most visibly dusty job was that of the mixers who had to open bags of dry powdered materials and tip them into hoppers. This was carried out on raised platforms (about 8-10 $\mathrm{m}$ high). Temperatures in the hoppers were around $135^{\circ} \mathrm{C}$, the result of frictional heat from blending. The hoppers were equipped with local exhaust ventilation.

Heating and extrusion took place at the floor level. The extruded pellets were collected and packed by the packers who were exposed to a relatively low level of dust. Other less exposed workers were forklift drivers, storemen, mechanics, fitters, elec:ricians, material testers, cleaners etc.

\section{STUDY POPULATION}

A total of 72 male workers were studied, consisting of 24 mixers, 24 low exposure non-mixers, and 24 nonPVC controls. All mixers in the three factories were invited to participate in the study. The 24 mixers represent $80 \%$ of all mixers. The low exposure PVC workers and the non-PVC controls were matched with the mixers for age ( \pm five years), race, and smoking state. The low exposure PVC workers were for example, forklift drivers, storemen, maintenance staff, and material testers from the same three PVC factories. The non-PVC controls were mechanics and maintenance staff from a marine police workshop with no exposure to PVC dust or any known asthma inducing agents. 
PEFR RECORDING

Each participant was given a mini-Wright peak flow meter and instructed in its correct use. He was asked to perform three blows after maximal inspiration on each occasion and to record the results on a form. The highest of the three readings was taken. Six daily recordings (every three hours) during the waking hours were made for one week (six working days and one day off). Recording started on a Monday and were made both at the workplace and at home.

The diurnal variation in PEFR was calculated as the difference between the highest and lowest PEFR values as a percentage of the highest PEFR on each day. For each worker the mean diurnal variation for the one week period was calculated.

\section{PULMONARY FUNCTION}

Forced expiratory volume in one second $\left(\mathrm{FEV}_{1}\right)$ and forced vital capacity (FVC) were performed on a dry wedge spirometer (Vitalograph) on Monday mornings when workers began their shifts. The spirometer was calibrated before use. The best $\mathrm{FEV}_{1}$ and best FVC were taken from three technically satisfactory forced expiratory manoeuvres where the best two recordings were within $5 \%$ of each other. All values were corrected to body temperature and pressure saturation. Height (to the nearest centimetre) was measured without shoes. Predicted normal values for $\mathrm{FEV}_{1}$ and $\mathrm{FVC}$ were calculated based on regression equations developed by $\mathrm{Zee}^{6}$ for local Chinese and Malay men.

\section{RESPIRATORY QUESTIONNAIRE}

Each subject was interviewed by a trained field investigator using a structured questionnaire. Data were obtained on pulmonary symptoms, personal biodata, detailed work history including previous employment, past medical history, atopy, and smoking habits.

\section{ENVIRONMENTAL ASSESSMENT}

A total of 45 personal breathing zone samples of respirable PVC dust were collected over two to four hours on cellulose ester membrane filters of $37 \mathrm{~mm}$ diameter and $8.0 \mu \mathrm{m}$ pore size using SKC personal dust sampling equipment at flow rates of $2.01 /$ minute. Twenty one samples were taken from mixers and 24 samples from less exposed workers (non-mixers).

A total of eight static samples of air were collected for analysis of hydrogen chloride $(\mathrm{HCl})$ and vinyl chloride monomer (VCM) (four each). Sampling was taken from four points: one near the mixer (on the platform), two near the extruder (floor level), and one outside the factory (ambient air). Sampling duration was three hours. For $\mathrm{HCl}$ sampling, air was drawn through an impinger at $1 \mathrm{l} / \mathrm{min}$. Air was drawn through a charcoal tube at $80 \mathrm{ml} / \mathrm{min}$ for $\mathrm{VCM}$ sampling. Analysis was by liquid chromatography for $\mathrm{HCl}$ and by gas chromatography for VCM.

\section{STATISTICAL ANALYSIS}

Statistical methods to compare exposed workers and controls were analysis of variance (F test), $t$ test for independent quantitative variables, $\chi^{2}$ test, and Fisher's exact test.

\section{Results}

ENVIRONMENTAL ASSESSMENT

Respirable dust concentrations for mixers (21 samples) ranged from 0.2 to $2.9 \mathrm{mg} / \mathrm{m}^{3}$ with a mean of $1.6 \mathrm{mg} / \mathrm{m}^{3}$. Respirable dust concentration for nonmixers (24 samples) ranged from 0.1 to $1.0 \mathrm{mg} / \mathrm{m}^{3}$ with a mean of $0.4 \mathrm{mg} / \mathrm{m}^{3}$.

Hydrogen chloride and VCM were not detected in any of the eight samples taken (detection limit $=0.03 \mathrm{mg} / \mathrm{m}^{3}$ for both $\mathrm{HCl}$ and $\mathrm{VCM}$ ).

\section{STUDY POPULATION}

Among the 72 subjects, $33.3 \%$ were Malays and the rest Chinese. Fifty four per cent were smokers (including $17 \%$ ex-smokers). Tables $1-3$ summarise personal data, prevalence of respiratory symptoms, and results of lung function tests and PEFR monitoring of these subjects. Non-PVC subjects were taller than those in the other groups. Although they

Table 1 Characteristics of study population

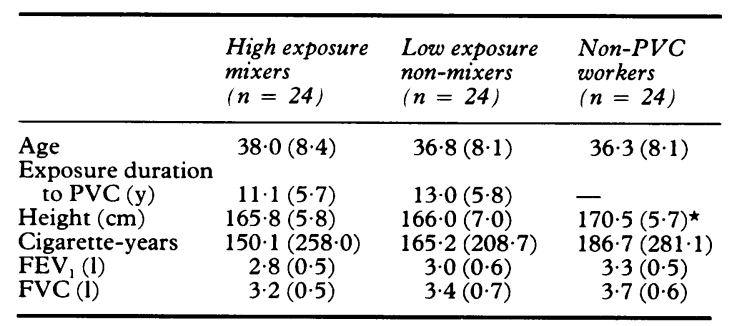

Data are given as mean (SD).

${ }^{\star} \mathrm{p}<0.05$ (ANOVA).

Table 2 Prevalence of symptoms

\begin{tabular}{llll}
\hline & $\begin{array}{l}\text { High exposure } \\
\text { mixers } \\
(n=24)\end{array}$ & $\begin{array}{l}\text { Low exposure } \\
\text { non-mixers } \\
(n=24)\end{array}$ & $\begin{array}{l}\text { Non-PVC } \\
\text { workers } \\
(n=24)\end{array}$ \\
\hline Cough & $4(16 \cdot 7)$ & $2(8 \cdot 3)$ & $2(8 \cdot 3)$ \\
Phlegm & $6(25 \cdot 0)$ & $4(16 \cdot 7)$ & $1(4 \cdot 2)$ \\
Rhinitis & $5(20 \cdot 8)$ & $7(29 \cdot 2)$ & $5(20 \cdot 8)$ \\
Eye irritation & $4(16 \cdot 7)$ & $1(4 \cdot 2)$ & $1(4 \cdot 2)$ \\
Breathlessness & $3(12 \cdot 5)$ & $2(8 \cdot 3)$ & $1(4 \cdot 2)$ \\
Wheeze & $7(29 \cdot 2) \star$ & $1(4 \cdot 2)$ & $0(0)$ \\
\hline
\end{tabular}

Data are given as number ( $\%)$ with positive symptoms.

${ }^{\star} \mathrm{p}=0.002$ ( $\chi^{2}$ test); $\mathrm{p}=0.005$ compared with non-PVC controls (Fisher's test); $\mathrm{p}=0.02$ compared with low exposure non-mixers (Fisher's test). 
Table 3 Results of lung function and PEFR

\begin{tabular}{|c|c|c|c|}
\hline & $\begin{array}{l}\text { High exposure } \\
\text { mixers } \\
(n=24)\end{array}$ & $\begin{array}{l}\text { Low exposure } \\
\text { non-mixers } \\
(n=24)\end{array}$ & $\begin{array}{l}\text { Non-PVC } \\
\text { workers } \\
(n=24)\end{array}$ \\
\hline $\begin{array}{l}\% \text { Predicted FEV } 1 \\
\% \text { Predicted FVC } \\
\text { FEV } / \text { FVC (\%) } \\
\text { DV PEFR }(\%)\end{array}$ & $\begin{array}{l}90.4(10 \cdot 8)^{\star} \\
90.9(12 \cdot 5) \\
86.5(6 \cdot 1) \\
6.5(4 \cdot 2)^{\star \star}\end{array}$ & $\begin{array}{c}94 \cdot 2(13 \cdot 7) \\
93 \cdot 4(12 \cdot 6) \\
87 \cdot 1(4 \cdot 6) \\
4 \cdot 8(2 \cdot 3)\end{array}$ & $\begin{array}{c}97.6(10.9) \\
96.9(10.9) \\
87 \cdot 4(5.6) \\
4.3(2 \cdot 3)\end{array}$ \\
\hline
\end{tabular}

Data are given as mean (SD).

${ }^{\star} \mathrm{p}=0.03$ compared with non-PVC controls $(t$ test $)$.

$\star \star \mathrm{p}=0.03$ compared with non-PVC controls $(t$ test); $\mathrm{p}=0.05$ compared with low exposure non-mixers ( $t$ test).

smoked more, this was not statistically significant (table 1). More mixers complained of wheeze than did other subjects. No significant difference was found in the prevalence of other symptoms (table 2). The FEV 1 of the mixers was $10 \%$ below the predicted values whereas that of the non-PVC subjects was $2 \%$ below the predicted values $(p=0.03)$. The mean diurnal variation in PEFR of the mixers of $6.5 \%$ was higher than either of the other control groups (table 3). Six mixers had a diurnal variation of greater than $15 \%$ on at least one day compared with none among the other groups $(p=0.01$, Fisher's test). The highest diurnal variation in a day was $23.9 \%$ in a mixer.

\section{Discussion}

Diurnal variation has been studied in workers exposed to grain dust ${ }^{7}$ and tobacco dust. ${ }^{8}$ It has been shown that age and smoking were significantly correlated in a positive fashion with diurnal variation in PEFR. The mixers in our study had a higher diurnal variation in their PEFR compared with both low exposure and non-PVC controls matched for age, smoking state, and race.

The diurnal variation in PEFR among PVC workers has not been investigated in any previous study. The median diurnal variation in PEFR of grain elevator workers was $5.9 \% .^{7}$ This is slightly higher than the median diurnal variation in PEFR of $4.8 \%$ for PVC mixers. The method for calculating diurnal variation in PEFR, however, for the grain elevator workers was different and resulted in a higher diurnal variation. The diurnal variation in PEFR was calculated as the difference between the highest and lowest PEFR values as a percentage of the mean PEFR on each day. In our case we expressed the difference as a percentage of the maximum PEFR on each day. Furthermore, the grain elevator workers were older (median age $=44$ years) and had higher prevalence of smoking ( $81 \%$ were smokers).

The mean diurnal variation in PEFR in a group of tobacco workers was $14.4 \%$ and for their controls, it was $9.5 \% .^{8}$ This is much higher than that seen in our subjects although method of calculating diurnal variation in PEFR was similar to ours. Their subjects were mainly women, however, and older (mean age $=43$ years). The prevalence of smoking was $43 \cdot 8 \%$. Also only four PEFR recordings were taken each day.

The higher prevalence of wheezing complaints and reduced $\mathrm{FEV}_{1}$ (below predicted values) among mixers compared with non-PVC controls provide further evidence that mixers in the PVC compounding industry may be exposed to a bronchoactive agent. We did not detect any overt cases of occupational asthma. This is however, not unexpected in a cross sectional study since we are likely to be studying a survivor population. We have recently completed a similar study of polyurethane foam operators exposed to toluene diisocyanate (TDI) (not yet published). No overt cases of occupational asthma were detected in this group of workers exposed to a known asthma inducing agent, TDI.

Possible asthma inducing agents in the PVC compounding industry include PVC dust, additives, and PVC decomposition products (for example $\mathrm{HCl}$, VCM). Among the additives, only azodicarbonamide is known to cause asthma but azodicarbonamide was not used in the three plants surveyed. So far dioctylphthalate (DOP) and other phthalate esters have not been identified as asthma inducing. ${ }^{10}$ Furthermore, the DOP was in liquid form. Other additives such as stabilisers (for example, lead, barium, cadmium, and zinc salts) are not likely to cause asthma. Polyvinylchloride is thermally stable at temperatures below $225^{\circ} \mathrm{C} .{ }^{11}$ Above $225^{\circ} \mathrm{C}$, PVC will degrade, releasing first $\mathrm{HCl}$ and then, above $300^{\circ} \mathrm{C}$, carbon monoxide, carbon dioxide, benzene, and VCM. Above $600^{\circ} \mathrm{C}$ small amounts of phosgene and chlorine are formed. Under normal operating conditions, temperatures do not exceed $170^{\circ} \mathrm{C}$. At the mixing station, temperatures do not exceed $135^{\circ} \mathrm{C}$. Hydrogen chloride and VCM were not detected in the vicinity of the mixer or the extruder.

The bulk of the dust is PVC. That unheated PVC dust can induce asthma has been shown by a positive challenge test. ${ }^{1}$ Our study provides further evidence of a significant effect of variable acute airway constriction from exposure to PVC dust.

1 Lee HS, Yap J, Wang YT, Lee CS, Tan KT, Poh SC. Occupational asthma due to unheated polyvinylchloride resin dust. Br J Ind Med 1989;46:820-2.

2 Ernst P, De Guire L, Armstrong B, Theriault G. Obstructive and restrictive ventilatory impairment in polyvinylchloride fabrication workers. Am J Ind Med 1988;14:273-9.

3 Baser M, Tockman MS, Kennedy TP. Pulmonary function and respiratory symptoms in polyvinylchloride fabrication workers. Am Rev Respir Dis 1985;131:203-8.

4 Soutar CA, Copland LH, Thornley PE, Ottery J, Adams WGF, Bennet B. Epidemiological study of respiratory disease in workers exposed to polyvinylchloride dust. Thorax 1980;35:644-52.

5 Soutar CA, Gould S. Clinical studies of workers exposed to polyvinylchloride dust. Thorax 1983;38:834-9.

$6 \mathrm{Zee} \mathrm{KO}$. Ventilatory function in normal industrial workers in 
Singapore. Proceedings of the XII Singapore-Malaysia Congress of Medicine, the Academy of Medicine, Singapore, 1977:587-95.

7 Revsbech P, Anderson G. Diurnal variation in peak expiratory flow rate among grain elevator workers. $\mathrm{Br} J$ Ind Med 1989;46:566-9.

8 Lander F, Gravesen S. Respiratory disorders among tobacco workers. Br J Ind Med 1988;45:500-2.

9 Slovak AJM. Occupational asthma caused by a plastics blowing agent, azodicarbonamide. Thorax 1981;36:906-9.

10 Nielsen J, Akesson B, Skerfving S. Phthalate ester exposure. Air levels and health of workers processing polyvinylchloride. $\mathrm{Am}$ Ind Hyg Assoc $J$ 1985;46:643-7.

11 Froneberg B, Johnson PL, Zandrigan PJ. Respiratory illness caused by overheating of polyvinylchloride. Br J Ind Med 1982;39:239-43.

Accepted 1 October 1990

\section{Vancouver style}

All manuscripts submitted to the $B r J$ Ind Med should conform to the uniform requirements for manuscripts submitted to biomedical journals (known as the Vancouver style).

The $\mathrm{Br} J$ Ind Med, together with many other international biomedical journals, has agreed to accept articles prepared in accordance with the Vancouver style. The style (described in full in $\mathrm{Br}$ Med J, 24 February 1979, p 532) is intended to standardise requirements for authors.

References should be numbered consecutively in the order in which they are first mentioned in the text by Arabic numerals above the line on each occasion the reference is cited (Manson ${ }^{1}$ confirmed other reports $\mathrm{r}^{2-5} \ldots$.). In future references to papers submitted to the $\mathrm{Br} J$ Ind Med should include: the names of all authors if there are six or less or, if there are more, the first three followed by et al; the title of journal articles or book chapters; the titles of journals abbreviated according to the style of Index Medicus; and the first and final page numbers of the article or chapter.

Examples of common forms of references are:

1 International Steering Committee of Medical Editors. Uniform requirements for manuscripts submitted to biomedical journals. Br Med J 1979;1:532-5.

2 Soter NA, Wasserman SI, Austen KF. Cold urticaria: release into the circulation of histamine and eosino-phil chemotactic factor of anaphylaxis during cold challenge. N Engl J Med 1976;294:687-90.

3 Weinstein L, Swartz MN. Pathogenic properties of invading micro-organisms. In: Sodeman WA Jr, Sodeman WA, eds. Pathologic physiology: mechanisms of disease. Philadelphia: W B Saunders, 1974:457-72. 